\title{
Diagnosis and follow-up of type 2 diabetes in women with PCOS: a role for OGTT?
}

\author{
Marianne Andersen and Dorte Glintborg \\ Department of Endocrinology, Odense University Hospital, Odense, Denmark
}

\author{
Correspondence \\ should be addressed \\ to $M$ Andersen \\ Email \\ msa@rsyd.dk
}

\begin{abstract}
Polycystic ovary syndrome (PCOS) is common in premenopausal women. The majority of women with PCOS have insulin resistance and the risk of type 2 diabetes mellitus (T2D) is higher in women with PCOS compared to controls. In non-pregnant women with PCOS, glycemic status may be assessed by oral glucose tolerance test (OGTT), fasting plasma glucose (FPG) or HbA1c. OGTT has been reckoned gold standard test for diagnosing T2D, but OGTT is rarely used for diagnostic purpose in other non-pregnant individuals at risk of T2D, apart from PCOS. OGTT has questionable reproducibility, and high sensitivity of the 2-h glucose value is at the expense of relatively low specificity, especially regarding impaired glucose tolerance (IGT). Furthermore, lean women with PCOS are rarely diagnosed with T2D and only few percent of normal-weight women have prediabetes. Glycemic status is necessary at diagnosis and during follow-up of PCOS, especially in women with high risk of T2D (obesity, previous gestational diabetes (GDM)). We suggest that OGTT should be used in the same situations in PCOS as in other patient groups at risk of T2D. OGTT is indicated for diagnosing GDM; however, OGTT during pregnancy may not be indicated in lean women with PCOS without other risk factors for GDM.
\end{abstract}

\section{Introduction}

Polycystic ovary syndrome (PCOS) is the most frequent endocrine condition in women, but the diagnosis of PCOS is only possible during premenopausal years (1). The Rotterdam Criteria are used to establish the diagnosis of PCOS when other causes of the clinical phenotype are excluded (1). PCOS is characterized by insulin resistance and hyperinsulinemia and insulin resistance is closely associated with obesity in PCOS (2). The prevalence of type 2 diabetes mellitus (T2D) is increased in PCOS. Recently, we reported that the hazard ratio of T2D in Danish women with PCOS was 4 compared to controls (3), which corresponded to findings from previous metaanalyses in mixed study populations of women with PCOS $(4,5,6,7)$. Validated diagnostic criteria are necessary to diagnose T2D in PCOS, but which diagnostic tool should be preferred is currently debated: Circulating glucose (fasting plasma glucose (FPG) or during oral glucose challenge, 2-h glucose) or hemoglobinA1c (HbA1c).

The aim of assessing glycemic status in PCOS is to diagnose T2D or prediabetes. Furthermore, determination of glycemic status can be a measure of insulin resistance in PCOS and glycemic status may help selecting which women need closer prospective follow-up regarding cardiometabolic risk (Fig. 1). It is important to notice that prediabetes is neither normal glucose metabolism or an actual disease, but rather a risk factor for future T2D and cardiovascular disease (CVD). In PCOS, a diagnosis of prediabetes can also be used as an indication for metformin therapy (8). Glycemic status is included in the various definitions of metabolic syndrome. In PCOS, metabolic syndrome is defined as impaired glucose tolerance (prediabetes), waist circumference $\geq 88 \mathrm{~cm}$, blood www.eje-online.org

https://doi.org/10.1530/EJE-18-0237
(C) 2018 European Society of Endocrinology Printed in Great Britain
Published by Bioscientifica Ltd. 
Glycemic status in PCOS

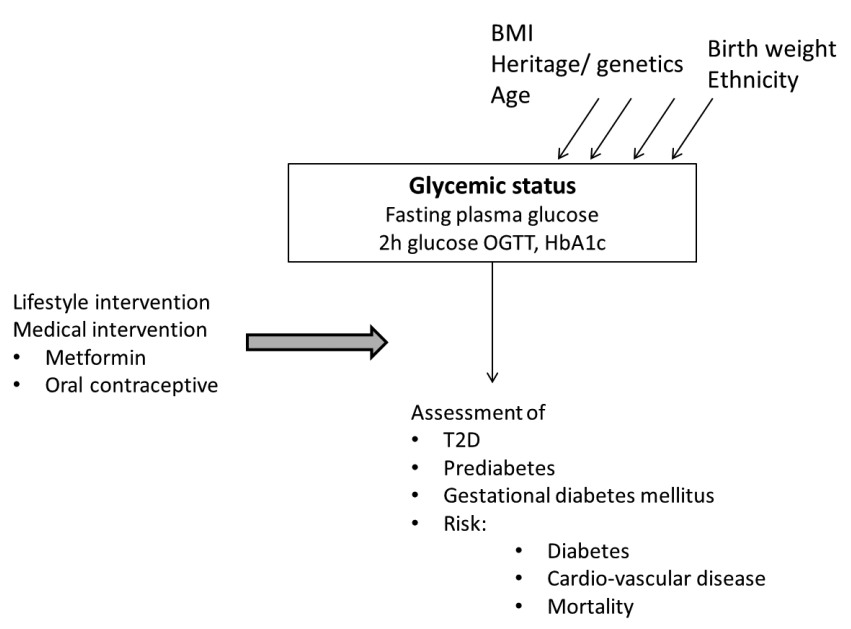

\section{Figure 1}

Glycemic status in PCOS is influenced by various factors, and treatment of PCOS will modify risk of type 2 diabetes mellitus, cardiovascular disease and mortality..

pressure $>130 / 85 \mathrm{mmHg}$, high-density lipoprotein (HDL) $<1.3 \mathrm{mmol} / \mathrm{L}$ and triglyceride (TG) $>1.7 \mathrm{mmol} / \mathrm{L}$ (9). It has been estimated that about $33 \%$ of women with PCOS fulfill one or more criteria of the metabolic syndrome (10) and international guidelines recommend that all newly referred women with PCOS are screened for the elements of the metabolic syndrome to detect women with high cardiometabolic risk (10), but the best marker for glycemic status in PCOS is debated (11). Recommendations regarding oral glucose tolerance test (OGTT) at the time of PCOS diagnosis and follow-up vary between PCOS professionals. At one end of the spectrum, the Australian guideline recommends OGTT at diagnosis of PCOS and annually during follow-up, whereas European Society of Human Reproduction and Embryology/American Society for Reproductive Medicine (ESHRE/ASRM) only recommends OGTT if BMI is $\geq 27 \mathrm{~kg} / \mathrm{m}^{2}$, and there is no mentioning of OGTT during follow-up (Table 1) (11). Should OGTT be recommended in all women with newly diagnosed PCOS and what are the pros and cons regarding OGTT during follow-up in PCOS (Table 2)?

Pre-pregnancy and pregnancy are times, where glycemic status is very important for the developing offspring and for the individual woman. The risk of gestational diabetes mellitus (GDM) was significantly increased in women with PCOS $(12,13)$. In general, OGTT is gold standard for diagnosing GDM, but the optimal cutoff value for 2-h glucose during OGTT in pregnancy and alternatively for FPG are debated $(14,15)$. Furthermore, should all women have an OGTT performed already when pregnancy is planned?

Table 1 International guidelines regarding OGTT upon diagnosis of PCOS.

\begin{tabular}{|c|c|c|}
\hline Guidelines & $\begin{array}{l}\text { OGTT recommended upon diagnosis in all } \\
\text { women with PCOS? }\end{array}$ & Follow up OGTT \\
\hline $\begin{array}{l}\text { Joint AACE/ACE and AE-PCOS } \\
\text { society }\end{array}$ & Yes & $\begin{array}{l}\text { Yearly in women with IGT } \\
\text { Every } 1-2 \text { years based on BMI (not specified) } \\
\text { and family history of T2D }\end{array}$ \\
\hline Australian NHMRC & Yes & $\begin{array}{l}\text { Every } 2 \text { years } \\
\text { Annually if additional risk factors for T2D* }\end{array}$ \\
\hline Endocrine Society & Yes & $\begin{array}{l}\text { Every } 3-5 \text { years } \\
\text { Sooner if additional risk factors for T2D** }\end{array}$ \\
\hline $\begin{array}{l}\text { Royal College of Obstetricians } \\
\text { and Gynecologists }\end{array}$ & $\begin{array}{l}\text { No } \\
\text { Recommended if one or more: } \\
\text { BMI } \geq 25 \mathrm{~kg} / \mathrm{m}^{2} \text {, age } \geq 40 \text { years, previous } \\
\text { gestational diabetes, or family history of T2D }\end{array}$ & Annually in women with IGT or IFG \\
\hline AE-PCOS Society & $\begin{array}{l}\text { No } \\
\text { Recommended if one or more: } \\
\text { BMI } \geq 30 \mathrm{~kg} / \mathrm{m}^{2} \text {, age } \geq 40 \text { years, previous } \\
\text { gestational diabetes, or family history of T2D }\end{array}$ & $\begin{array}{l}\text { Every } 2 \text { years in women with risk factors*** } \\
\text { Sooner if additional risk factors for T2D } \\
\text { develop***}\end{array}$ \\
\hline ESHRE and ASRM & $\begin{array}{l}\text { No } \\
\text { Recommended if } B M I \geq 27 \mathrm{~kg} / \mathrm{m}^{2}\end{array}$ & Not specified \\
\hline $\begin{array}{l}\text { *Age, gender, ethnicity, parental hist } \\
\text { inactivity, waist circumference; }{ }^{*} \text { cen } \\
\text { hypertension, IGT or subclinical vascL } \\
\text { AACE, Association of Clinical Endocri } \\
\text { American Society for Reproductive } N \\
\text { impaired glucose tolerance; NHMRC, } \\
\text { T2D, type } 2 \text { diabetes. }\end{array}$ & $\begin{array}{l}\text { ory of diabetes, history of high blood glucose levels, use } \\
\text { tral adiposity, substantial weight gain, and/or symptoms } \\
\text { lar disease. } \\
\text { nologists; ACE, American College of Endocrinology; AE-P } \\
\text { edicine; ESHRE, European Society of Human Reproductio }\end{array}$ & $\begin{array}{l}\text { antihypertensive medications, smoking, physical } \\
\text { diabetes; ***obesity, cigarette smoking, dyslipidemia, } \\
\text { S society, Androgen Excess and PCOS society; ASRM, } \\
\text { and Embryology; IFG, impaired fasting glucose; IGT, } \\
\text { lucose tolerance test; PCOS, polycystic ovary syndrome }\end{array}$ \\
\hline
\end{tabular}


Table 2 Arguments for OGTT in PCOS and corresponding counter-arguments.

Argument for OGTT
OGTT is important for diagnosing T2D and
prediabetes in women with PCOS - at PCOS
diagnosis and during follow up
Considered gold standard test for T2D
ADA and WHO agree about the cut-off for IGT
Can be performed in various settings (hospital,
private clinic, at home)
Costs can be kept low (e.g. only measure $2 \mathrm{~h}$ CBG e.g.
India)
FPG and HbA1C are not widely available
Standardized test - easy to perform
High sensitivity compared to FPG and HbA1c
regarding diagnosis of IGT and T2D
Can be applied in patients with iron deficiency, sickle
cell trait etc.
Diagnosis of T2D and prediabetes important for risk
of future CVD
Diagnosis of IGT could determine treatment with
metformin
OGTT can be used to determine insulin resistance in
PCOS
Can be used to determine metabolic status during
metformin and oral contraceptive treatment
Prediabetes screening is important before pregnancy
in PCOS
Gold standard for diagnosing GDM

\section{Counter-argument}

HbA1c or FPG may be used for assessing glycemic status in most cases, however the setting needs to be considered

OGTT as gold standard test may be questioned due to high variability of the test

95 percentile is used as cut-off for IGT, resulting in a high number of false positive patients

High variability - two tests needed for diagnosis of T2D. $\mathrm{HbA} 1 \mathrm{C}$ is more robust

HbA1c and FPG are cheaper than OGTT in many countries

HbA1c could be superior to OGTT regarding metabolic risk and CVD Dependent of height - one size does not fit all? Risk of over-diagnosis of T2D and IGT in women with low height?

Over-diagnosis of IGT, T2D? Quality of life may be negatively influenced by a diagnosis of IGT

Not recommended after bariatric surgery

HbA1c, sCD36, IL-6 or other markers could be superior to OGTT as screening markers for risk of future CVD

Treatment with lifestyle modification and metformin is not dependent of OGTT, but should be considered in the majority of women with PCOS

Waist and BMI are the best markers of insulin resistance in PCOS

There are insufficient data to recommend prospective OGTTs during medical treatment in PCOS

Screening for metabolic risk before pregnancy could include HbA1c, BMI and waist measurements

The cut-off for CBG in OGTT to diagnose GDM is not settled. The risk for GDM in PCOS is dependent of BMI

CBG, capillary blood glucose; CVD, cardiovascular disease; FPG, fasting plasma glucose; GDM, gestational diabetes; IGT, impaired glucose tolerance; T2D, type 2 diabetes.

\section{The case in favor of OGTT in PCOS}

\section{OGTT as a diagnostic method for T2D}

OGTT has been used for more than 40 years and the test is available worldwide. The test is usually considered gold standard for diagnosing diabetes. The international definition of T2D during a 2-h $75 \mathrm{~g}$ OGTT is a 2-h glucose value $\geq 11.1 \mathrm{mmol} / \mathrm{L}$ (16). The OGTT can be performed at a hospital setting, at a laboratory or may be performed at the patient's home by a health professional. In some countries, only 2-h glucose is assessed in capillary blood using a small portable device, and hence, the cost of the OGTT can be kept low. Alternative methods for diagnosing T2D are FPG and/or HbA1c. The cut-off for FPG is $\geq 7.0 \mathrm{mmol} / \mathrm{L}$ (16). The use of FPG for determining glycemic status has drawbacks and advantages compared to OGTT. FPG requires fasting for $8 \mathrm{~h}$ (17) in line with OGTT, and the glucose analysis should be performed in venous plasma (17). FPG has less sensitivity but increased specificity compared to 2 -h glucose $(18,19)$.
International guidelines support that values of $\mathrm{HbA} 1 \mathrm{c}$ $>48 \mathrm{mmol} / \mathrm{mol}(\geq 6.5 \%)$ can be applied for diagnosing T2D in asymptomatic patients (20), whereas HbA1c levels between 6 and $6.4 \%(42-47 \mathrm{mmol} / \mathrm{mol})$ should be followed by an OGTT and HbA1c levels below 6\% require no further tests (20). The cut-off point for HbA1c is largely based on the established association between HbA1c and microvascular disease (20). HbA1c reflects the average blood glucose levels during a 2- to 3-month period in persons a normal erythrocyte life cycle (20). When OGTT is considered the gold standard for diagnosing T2D, HbA1c may not be appropriate for diagnosing T2D. In PCOS, we found that 20 women out of 208 had T2D according to OGTT, whereas only 7/208 women had elevated HbA1c (21). The sensitivity of HbA1c $\geq 6.5 \%$ as a diagnostic test for T2D compared to OGTT was only 35\%, whereas the specificity of HbA1c was $99 \%$, and the more severe cases of T2D diagnosed by OGTT were also identified by HbA1c (21). Low diagnostic performance of HbA1c compared to OGTT for the diagnosis of T2D was also reported in non- 
PCOS populations $(22,23,24)$. Previous studies evaluated the consequence of reducing the HbA1c cut-off to $6.0 \%$ (24) and reported that the sensitivity of HbA1c compared to the OGTT increased from 35 to 50\%, however, specificity only decreased from 99 to $96 \%$.

The prevalence of impaired glucose tolerance (IGT) in PCOS was up to $36 \%$ and the odds ratio for IGT was 2.48 (95\% CI 1.63-3.77) in women with PCOS compared with controls (25). In the general population, around 5-10\% individuals with prediabetes convert to diabetes per year and up to $70 \%$ individuals with prediabetes will develop T2D (26). Prediabetes may be diagnosed by IGT, IFG or HbA1c in the gray zone. However, the cut-offs for glucose and $\mathrm{HbA1c}$ are unsettled. American Diabetes Association (ADA) and World Health Organization (WHO) have consensus regarding cut-off limits for IGT, whereas the cutoffs for IFG are $5.6 \mathrm{mmol} / \mathrm{L}$ (ADA) and $6.0 \mathrm{mmol} / \mathrm{L}$ (WHO) (27). The cut-off for prediabetes, using HbA1c, is $42 \mathrm{mmol} /$ mol (6.0\%), according to $\mathrm{WHO}$ and the International Expert Committee, whereas the cut-off according to ADA is $39 \mathrm{mmol} / \mathrm{mol}$ (5.7\%) (27). In our previous study in PCOS, all patients with IGT during OGTT had HbA1c levels $<6.5 \%$ and the sensitivity for $\mathrm{HbA} 1 \mathrm{c} \geq 6.5 \%$ as diagnostic test for abnormal glucose tolerance compared to the OGTT was only $13 \%$ (21). HbA1c therefore seems to be a poor marker of IGT and 2-h glucose is the most sensitive test for diagnosing prediabetes.

\section{OGTT as a marker of insulin resistance}

Central obesity is associated with insulin resistance and predicts the development of T2D and CVD (28). MRI is considered gold standard for measurement of regional fat mass, but is not generally available in a clinical setting (29). Weight and BMI are the simplest methods for the establishment of total body fat, and waist circumference is a good estimate of abdominal fat (30). Therefore, weight, BMI and waist measurements should be applied in all newly referred women with PCOS (31). In addition, whole-body DXA scans make it possible to estimate abdominal and extremity fat mass (32). This method does not distinguish intra-abdominal fat mass from subcutaneous fat mass, but subcutaneous abdominal and intra-abdominal fat could have similar adverse effects on insulin resistance (33). BMI was the most important predictive factor for the development of T2D in prospective studies in PCOS (34). We recently compared fat distribution in women with PCOS vs controls and established the best measure of fat mass to predict insulin resistance in PCOS (35). Women with PCOS had higher central fat mass (waist, waist-to- hip ratio (WHR) and upper/lower fat ratio) compared to controls. Trunk fat, waist and BMI were the best predictors of homeostatis model of insulin resistance (HOMA-IR) in PCOS (35). These findings supported that BMI and waist measurements could predict insulin resistance in women with PCOS. Insulin sensitivity is most reliably measured by a hyperinsulinemic-euglycemic glucose clamp method. However, in favor of OGTT - also in PCOS, Abdul-Ghani et al. (36) showed that IGT showed closer association with total glucose disposal during a hyperinsulinemiceuglycemic clamp than IFG. Furthermore, the 2-h glucose level during OGTT is less fluctuating than FPG, as OGTT is a standardized challenge test. IGT is an important predictor of future T2D in patients with PCOS $(37,38)$ and a diagnosis of IGT may be used in the daily clinic to identify patients who may benefit the most from lifestyle and medical intervention.

\section{OGTT during preconception and pregnancy}

In pregnancy, maternal insulin sensitivity changes to accommodate fetal glucose needs and insulin resistance prevail in the third trimester (39). GDM complicates 2-3\% of pregnancies in Denmark (40). Maternal hyperglycemia is associated with excessive fetal growth and increased need for cesarean delivery (41). The intrauterine environment in women with PCOS is influenced by maternal obesity, hyperinsulinemia, androgen excess and elevated fat mass in the offspring at birth (42) and later in life (43). Therefore, women with T2D or IGT should be identified as early as possible for example during preconception care and during fertility treatment (44). Individual screening for metabolic risk and initiation of lifestyle intervention and metformin treatment should be considered in all women with PCOS, who are seeking advice for fertility treatment. The time during preconception care could indeed be a window of opportunity to investigate and treat adverse metabolic risk in PCOS.

OGTT is considered gold standard test to diagnose GDM. At present, there is conflicting evidence whether PCOS per se increases the risk of GDM or whether obesity is the key factor (15). We recently reviewed 30 studies regarding GDM in PCOS and found that the prevalence of GDM in PCOS and controls varied widely (1.1-55.7\% in PCOS and $0.6-30.4 \%$ in controls) (15). Data were not uniform and study cohorts varied widely, but higher BMI, higher age, Asian ethnicity and fertility treatment were associated with increased risk of GDM in PCOS. In a relatively lean Danish cohort, the prevalence of GDM was similar in women with PCOS and controls independent 
of applied diagnostic criteria for GDM (15). Pregnancy in PCOS is characterized by factors known to increase risk of GDM, especially high BMI and fertility treatment, whereas PCOS may not be an individual risk factor for GDM. Criteria for individual risk assessment are not available in PCOS, and until then, OGTT should be performed during pregnancy in all women with PCOS.

\section{OGTT as a marker of long-term metabolic risk and CVD}

Insulin resistance, low-grade inflammation and central obesity in PCOS could be associated with increased risk of development of CVD. Coronary artery calcification and echocardiographic abnormalities were more common in women with PCOS compared to controls (45), but the risk for hard cardiovascular endpoints such as coronary heart disease and stroke in PCOS is debated. The OR for CVD in PCOS varied from 1.3 to 2.0 in recent meta-analyses $(4,5,6,7)$, but the association between CVD and PCOS was not significant in all studies $(4,5)$. In a Danish study population of women with PCOS, we found a hazard ratio (95\% CI) for development of CVD including hypertension and dyslipidemia of $1.7(1.6-1.8)$ and the total event rate of CVD was 22.6 per 1000 person years in women with PCOS vs 13.2 per 1000 person years in controls $(P<0.001)$ (46). When we excluded hypertension and dyslipidemia from the study outcome, the incidence rate for CVD was reduced to 6.4 per 1000 person years in PCOS vs 4.5 per 1000 person years in controls $(P<0.001)(46)$. Included women in the study were aged 29 (23-35) years (median (quartiles) at study inclusion and the follow-up was 11.1 (6.9-16.0) years (46). These findings supported that the risk for CVD should be considered also in young women with PCOS (46), but the absolute risk for CVD in premenopausal women with PCOS was low. The best glycemic marker for future CVD in PCOS is debated. In non-PCOS study populations, several studies suggested that HbA1c could be a better predictor of CVD and overall mortality than fasting or 2-h glucose during OGTT $(47,48)$. Populationbased studies found that higher HbA1c levels within the reference range were associated with higher risk for CVD $(49,50,51)$ and the lowest risk for CVD was observed in individuals with $\mathrm{HbA} 1 \mathrm{c}$ levels $<5 \%(50,51)$. Furthermore, HbA1c was more strongly associated with risk of CVD and death from any cause than fasting glucose (49). In agreement with this hypothesis, we previously performed OGTT and HbA1c in 208 premenopausal women with PCOS and found that HbA1c showed closer correlation with waist, BMI and lipid profile than 2-h BG during OGTT
(21). These results could be in favor of measuring HbA1c instead of performing OGTT to determine cardiovascular risk in PCOS (21). We further evaluated this hypothesis in 1165 women with PCOS and no previous diagnosis of CVD, dyslipidemia or hypertension (46). We found that HbA1c, fasting insulin and HOMA-ir were higher at baseline evaluation in women with PCOS who were diagnosed with CVD later on compared to women not diagnosed with CVD. In multiple regression analyses, 2-h glucose, fasting insulin and HOMA-ir predicted development of CVD after adjusting for age and BMI, whereas HbA1c did not predict CVD risk. Therefore, these study findings did not support that HbA1c was a better predictor of CVD than $2 \mathrm{~h}$ or fasting glucose (49). In our national study cohort of women with PCOS, a baseline diagnosis of diabetes, without considering diagnostic assessment method, increased the risk of CVD more than threefold, confirming that women with PCOS and diabetes need special attention regarding risk of CVD (46). Furthermore, the risk of CVD is closely associated with age, and the absolute risk for cardiovascular events in young women with PCOS is low. Medical treatment with statins, antihypertensives and blood diluting agents are rarely indicated in reproductive aged women with PCOS as there are limited safety data regarding treatment with the drugs during pregnancy (52). The prevalence for myocardial infarction was $27 \%$ in women with PCOS aged $>65$ years and the OR for myocardial infarction were 12.9 in women with PCOS aged $>65$ years vs controls (53). Furthermore, the risk for stroke was significantly increased in PCOS when only studies in women of average age $>45$ years were included (5). Increasing age in PCOS was associated with higher blood pressure, more adverse lipid profile, and impaired beta cell function (54). These findings suggest that the metabolic screening program in PCOS should be adjusted to take increasing age into account. Menopause status could be an important confounder when looking at the association between metabolic risk and age in PCOS. After menopause, levels of adrenal and ovarian androgens decrease, which could affect cardio-metabolic risk in PCOS. Decreased estrogen levels during menopause could be associated with metabolic dysfunction and deposition of visceral (and ectopic) fat (55). Testosterone has, previously, been associated with unfavorable metabolic factors in premenopausal women $(56,57)$. However, whether high androgens have a protective or unfavorable influence on the manifestation of CVD in women with PCOS has not been settled $(58,59)$. Interestingly, metabolic health may be better than expected in postmenopausal women with previous PCOS, as no strong positive associations were 
found between testosterone levels and risk of CVD (59). All the above findings underline the need for prospective, well-phenotyped cohort studies in postmenopausal women with a former PCOS diagnosis.

\section{Conclusion in favor of OGTT}

Women with PCOS have significantly increased risk of T2D compared to women without PCOS (3). OGTT is reckoned gold standard test for diagnosing diabetes and prediabetes (27) and OGTT is recommended for assessing glycemic status at time of diagnosing PCOS and during follow-up, independently of BMI (8). Especially in countries where FPG cannot be handled correctly and HbA1c is not valid, OGTT is a necessity. OGTT is often used in pre-pregnancy and of course during pregnancy to diagnose GDM.

\section{The case against OGTT in PCOS}

\section{No indication for OGTT in all women with PCOS}

Glycemic status needs to be evaluated in PCOS due to increased risk of T2D (3). OGTT has been considered gold standard test for diagnosing diabetes and prediabetes (27), and the Australian guideline for PCOS recommends that OGTT should be performed by time of the PCOS diagnosis and then repeated annually (11). The prevalence of PCOS is estimated to be $10-15 \%$ in reproductive aged women and adhering to the Australian guideline would result in performing a considerable number of OGTTs. Performing such a high number of OGTTs may not balance the cost for the individual woman, lost income and time or general cost for society (60). The recommendation for performing OGTT according to the last guideline from 2013, was more modest: 'Diagnosis and treatment of Polycystic Ovary Syndrome: An endocrine society clinical practice guideline: All women with PCOS should have an OGTT at time of PCOS diagnosis and every 3-5 years hereafter, unless the woman is unable or unwilling to complete an OGTT' (8). In agreement, ESHRE/ASRM recommended that OGTT is only indicated in overweight women (11). This last recommendation reflects that T2D or IGT are mainly diagnosed in overweight women $(11,18)$ as no one (11) or very few normal-weight women with PCOS had impaired glycemic status (18). Ollila et al. (61) reported that none of 62 lean Finnish women with self-reported PCOS developed T2D by 46 years of age and suggested that OGTT screening should be targeted to overweight and obese women with PCOS. Recently, Pelanis et al. (11) confirmed these results in a Nordic cohort of women with PCOS. No Nordic (0/298) woman was diagnosed with T2D using OGTT if BMI was below $25 \mathrm{~kg} / \mathrm{m}^{2}$. In agreement, other studies found very few patients with BMI $<25 \mathrm{~kg} / \mathrm{m}^{2}$ and T2D during OGTT: 0/298 (0\%) (62), 1/104 (0.9\%) (63) and 1/57 (1.8\%) (18).

Celik et al. (64) reported that obese women with PCOS were 4 times more prone to convert from normal glucose tolerance (NGT) to IGT than lean women with PCOS. Other papers confirmed that BMI was an independent risk factor $(34,65)$ for development of T2D in PCOS. Even in an Asian population, Li et al. (66) reported that impaired glucose metabolism with decreased insulin secretion was predominantly found in Chinese women with PCOS and BMI $>25.5 \mathrm{~kg} / \mathrm{m}^{2}$. $\beta$-Cell function was not impaired in normal-weight patients with PCOS, but insulin resistance was common in lean Chinese women with PCOS (67). These studies question the necessity for OGTT in lean women with PCOS.

Metabolic risk could be modified according to PCOS phenotype. Women fulfilling the National Institute of Health (NIH) criteria for PCOS could have higher metabolic risk than patients with milder phenotypes (68) and metabolic disturbances were more pronounced in women with PCOS and hyperandrogenism as compared to women with no hyperandrogenism (69). However, high testosterone and PCOS phenotype did not predict glycemic status in three studies, two recent Nordic studies $(3,11)$ and one Chinese study $(70)$. It is important to recognize that BMI differed between different Rotterdam phenotypes (11). Therefore, studies regarding metabolic risk in different PCOS phenotypes need to adjust for BMI.

\section{Problems with OGTT as a diagnostic method for T2D and IGT}

OGTT is rarely used as a diagnostic tool for T2D (71), except during pregnancy and in women with PCOS (11). A previous study on reproducibility of a standard $75 \mathrm{~g}$ 2-h OGTT concluded that the intra-individual variation in 2-h glucose determinations was so high that the continued use of an OGTT for a diagnostic purpose could be questioned (72). Therefore, a second OGTT is required in order to establish a diagnosis of diabetes mellitus if the first test is abnormal (27).

Furthermore, body composition may affect the result of OGTT along with genetics, diet and lifestyle $(73,74)$. South Asians tend to have significantly shorter stature, and reduced height could explain the higher incidence of IGT in women as compared to men, whereas more 
men more often have IFG (73). In contrast to negative associations between height and 2-h glucose, FPG and HbA1c were not significantly related to height (73). It is possible that the glucose load during an OGTT should be adjusted according to height and/or ethnicity (73). However, what is the real gold standard test for T2D? The cut-off level for 2-h blood glucose to diagnose diabetes was initially defined in a very high-risk group of individuals, the Pima Indian population, where glucose values were bi-modally distributed (75). In contrast to Pima Indians, other populations usually have a unimodal distribution of 2-h glucose values (75). In general, it is difficult to separate patients from healthy individuals in a unimodal distribution (75), whereas bimodal distributions enable a cut-off between healthy individuals and patients with T2D. A cut-off rarely ensures $100 \%$ sensitivity and $100 \%$ specificity, but in a bimodal distribution, it is possible to estimate sensitivity and specificity of various cut-offs. Cut-off limits are usually defined as the lower and upper boundaries of a $95 \%$ reference interval. Regarding risk of T2D or prediabetes, only the upper cut-off limit is of interest. The cut-off limit would correspond to the 97.5 percentile and by definition, $2.5 \%$ of healthy individuals would be false-positive individuals (76). WHO (16), actually, applied the 95 percentile for diagnosing IGT and thereby accepted 5\% false-positive tests (76). A change of cut-off limit will impact the sensitivity and specificity of a test. Clinicians may prioritize high sensitivity of diagnostic tests to avoid skipping a single patient, but falsepositive and false-negative diagnoses matter differently in various situations (60). A false-negative test result should be avoided when donor blood is screened for human immunodeficiency virus (HIV) infection, but diagnosing T2D or prediabetes is a different situation. If sensitivity should be close to $100 \%$, it would be at the expense of diagnosing healthy individuals with T2D or prediabetes. Receiver-operating characteristic (ROC) curves summarize accuracy of various cut-offs of f.x. 2-h glucose (60), and the graphical ROC curve may be very informative (60). ROC curves require a gold standard test. OGTT is reckoned a gold standard test to diagnose T2D, but considering the low reproducibility of 2-h glucose levels (72), the OGTT may disqualify for a gold standard status? Furthermore, ROC curves do not take disease prevalence into account.

It is important to notice that there is no accurate diagnostic test for prediabetes (27). The OGTT is more sensitive to diagnose prediabetes than FPG or HbA1c; however, this increased sensitivity may be at the expense of decreased specificity (76). In addition, cut-off limits for prediabetes differ between ADA (United States) and
WHO (27). Diagnosing an individual with prediabetes has large implications for many patients. Time consumed with testing, medication and especially stigma and worries should be considered before recommending the OGTT. Women with PCOS have lower scores for good quality of life compared to healthy controls (77) and higher prescription rate of antidepressants compared to controls (78). Importantly, many women with PCOS and IGT could have continued living relatively healthy normal lives without ever having either T2D and perhaps without increased risk of CVD (27). Therefore, performing an OGTT may not be needed even in women with an elevated risk of T2D, and measurement of FPG or HbA1c may be applied instead.

\section{Glycemic status and CVD, OGTT is not necessary}

The risk of T2D is low in most women with PCOS, but the risk for T2D increases along with $\mathrm{BMI}(3,11,18,61)$, and central obesity is associated with insulin resistance and increased levels of adipokines and inflammatory markers. High levels of inflammatory markers could predict the development of type 2 diabetes mellitus and CVD (79, 80). The foam cell formation process is initiated and enhanced by the binding of oxLDL to CD36 receptors, therefore making CD36 activity a risk factor of CVD (81). Women with PCOS had higher soluble CD36 levels than weight-matched controls (82) and soluble CD36 was inversely associated with insulin sensitivity and positively associated with lipid oxidation during insulin stimulation (83). Other promising cardiovascular risk markers in PCOS are hsCRP and IL-6 (31). Measurement of these markers has not been implemented in everyday clinic, and it remains to be established whether one or more of these markers could be better predictors of longterm cardiometabolic risk in PCOS than glycemic status established by OGTT.

Prediabetes may be an indication for metformin therapy. Furthermore, a diagnosis of prediabetes may focus the attention on other metabolic risk factors for CVD such as BP and lipid status (84). Lipid status should be assessed by the time of PCOS diagnosis (46), but statin treatment is rarely indicated in women with PCOS $<35$ years (52) as there is no evidence for treating all women with PCOS and a diagnosis of IGT as strict as patients with T2D (84). Data are needed to support an additional effect of knowing IGT status for the motivation and performance regarding weight loss and physical activity of the individual woman with PCOS. No data exist from large international studies regarding prediabetes and 
risk of CVD in PCOS. A recent study in ageing women and men reported that prediabetes defined by HbA1c was associated with a worse prognosis than prediabetes defined by FPG or 2-h glucose. However, the excess risk among individuals with prediabetes is mainly explained by the clustering of other cardiometabolic risk factors associated with hyperglycemia (85).

For now, a diagnosis of IGT is not mandatory as part of the cardiometabolic risk assessment in PCOS.

\section{OGTT during medical treatment?}

Lifestyle intervention and metformin are first-line treatment in overweight and obese women with PCOS, whereas the use of lifestyle and metformin treatment in normal weight women is less established. The aim of these treatment modalities is to promote weight loss, increase insulin sensitivity and to regulate menstrual cycles $(86,87)$. Weight loss around $5 \%$ is often sufficient to improve menstrual cycles and ovulation rate (86). Metformin is often considered second-line treatment in PCOS and the PCOS guideline from 2013 recommended metformin in women with PCOS with T2D or IGT who failed lifestyle modification (8). The number of women with PCOS, who fail lifestyle intervention, is very high, and metformin therapy is indicated in many women with PCOS. Metformin is efficacious in reducing weight in women with PCOS also before a derangement in glycemic status (88). Therefore, metformin may be of benefit also in women with PCOS and NGT. Treatment with metformin in lean women with PCOS was associated with a significant weight loss (88) and improved menstrual cycles (89), but lifestyle intervention in lean women with PCOS may not be first choice unless the woman has a disadvantageous metabolic risk profile. The effect of lifestyle and metformin treatment can be monitored by decreased weight and improved cycle regularity. But how should effect of lifestyle and metformin treatment on glycemic status be monitored? - Is it relevant to monitor glucose tolerance prospectively by OGTT in normal weight women with PCOS treated with metformin? Longterm studies regarding the effect of metformin treatment on insulin sensitivity and outcomes of OGTT in PCOS are limited. We recently performed a randomized controlled trial in 90 women with PCOS randomized to 12-month treatment with metformin $(2 \mathrm{~g} /$ day), oral contraceptives or metformin +oral contraceptives (90). Metformin treatment was associated with a significant weight loss of $-3.0(-10.3 ; 0.6) \mathrm{kg}$ (median (quartiles) $(88,90)$. T2D at study entry was an exclusion criterion $(88,90)$, but three women randomized to metformin treatment had IGT. During study intervention with metformin, two women with IGT converted to normal, but four women converted from normal glucose tolerance to IGT (unreported data) and area under the curve for glucose was unchanged (88). The study population was relatively lean with median BMI $25.1(22.7 ; 29.4) \mathrm{kg} / \mathrm{m}^{2}$ (median (quartiles)), which could have affected our study results. The study raises the question of the value of performing prospective OGTTs during medical treatment with metformin in lean women with PCOS. According to Tomlinson (91), no study has determined whether the incidence of $\mathrm{T} 2 \mathrm{D}$ is reduced during treatment with metformin $(91,92)$. Small observational studies reported conflicting results regarding the effect of metformin on glucose tolerance in PCOS (93), and we are not aware of international guidelines concerning prospective OGTTs in women with PCOS on metformin treatment. In a similar way, the relevance of performing prospective OGTTs in women with PCOS treated with oral contraceptive treatment (OCP) has not been determined. Treatment with OCP was associated with increased body weight (88) and OCP could have an adverse effect on insulin resistance $(87,94)$. Prospective screening for T2D is therefore very relevant in women with PCOS on OCP, but the optimal screening modality has not been clarified.

OGTT may not be indicated during medical therapy in PCOS and development of T2D may be diagnosed by HbA1c and/or FPG.

\section{Pregnancy and OGTT in PCOS}

It is mandatory to diagnose impairment in glycemic status during pre-pregnancy and in pregnancy as hyperglycemia should be avoided, especially in early pregnancy. Glycemic status may be assessed by HbA1c, FPG or 2-h glucose before pregnancy. The indication for OGTT before pregnancy is debated, but there is no evidence regarding the superiority of OGTT in this situation. By definition, many women with PCOS have irregular menses and pregnancy may not be fully planned; hence, it is difficult to plan the timing of an OGTT, whereas HbA1c may be easier to assess consecutively. Furthermore, in many cases, a diagnosis of IGT during OGTT will not change the handling of the individual woman with PCOS as lifestyle modification, weight loss and physical activity should always be recommended during planning of pregnancy.

During pregnancy, the situation is different. OGTT has, historically, been the test of choice for GDM. However, even though the WHO2013 criteria (95) have been accepted in Europe, a recent European survey 
reported that most European centers used risk factor assessment before an OGTT was performed (96). In accordance, The Danish Society for Obstetrics and Gynecology has endorsed the WHO2013 criteria (95), but the GDM diagnosis in Denmark follows the criteria stated by Jensen et al. (97). PCOS is a risk factor for GDM, but PCOS as a sole risk factor has not yet been implemented. In a prospective study in the Odense Child Cohort (98), we found no significant increase in GDM in women with PCOS compared to those without PCOS (15). The women in OCC were relatively lean, and the study included very few women of Asian origin.

There is a growing interest in FPG to determine glycemic status during pregnancy (14). However, a discussion of the cut-off for FPG is mandatory, as the number of pregnant women with GDM may be quite high in some populations. In accordance, we recently reported that applying the WHO2013 FPG threshold of $\geq 5.1 \mathrm{mmol} / \mathrm{L}$ (95) resulted in 40\% women with GDM (14). Ethnicity predicts the risk of GDM as especially Asian women had a high prevalence of GDM (99). However, the use of $3 \mathrm{~h} 100 \mathrm{~g}$ OGTT and $1 \mathrm{~h} 50 \mathrm{~g}$ OGTT for diagnosing GDM (99) could lead to overdiagnosis of GDM due to low height in Asian populations (73, 74).

\section{Bariatric surgery, GDM and OGTT}

Bariatric surgery in PCOS is associated with high weight loss, increased insulin sensitivity and improved ovulation rate $(100,101)$. The phenotype of PCOS often totally disappears after bariatric surgery and therefore supports an emerging concept that, in the presence of massive obesity, a secondary PCOS may develop. In Denmark, PCOS is considered an individual risk factor for obesity, and women with BMI $>35 \mathrm{~kg} / \mathrm{m}^{2}$ and a diagnosis of PCOS are bariatric surgical candidates. In a recent Danish study, the average weight loss in premenopausal women during the first postoperative year was $39.6 \mathrm{~kg}$ (102). Pregnancy should be avoided within 2 years after bariatric surgery and young fertile women should use safe birth control (103). Performing OGTT after bariatric surgery can trigger dumping syndromes and is generally not recommended (104). OGTT-induced dumping syndrome can lead to inaccurate results of the OGTT and the risk of reactive hypoglycemia was 55\% in previous studies (105). Screening for GDM in women with previous bariatric surgery should therefore not involve the OGTT. Instead, HbA1c can be measured at the first antenatal visit to exclude pre-existing diabetes, but later in pregnancy there are no data to support use of HbA1c. Instead, fasting, pre-and postprandialcapillaryblood glucosemeasurements are recommended to screen for GDM in pregnant women with previous bariatric surgery (104). The diagnostic or intervention thresholds for capillary blood glucose were $>5.3 \mathrm{mmol} / \mathrm{L}$ before meals, $>7.8 \mathrm{mmol} / \mathrm{L} 1 \mathrm{~h}$ after meals and $>6.4 \mathrm{mmol} / \mathrm{L} 2$ hours after meals according to National Institute for Health and Care Excellence (NICE) (https://www.nice.org.uk/guidance/ng3/).

\section{Metformin during pregnancy in PCOS}

Metformin may be applied as part of fertility treatment to improve pregnancy rate and the use of metformin may be continued during pregnancy to decrease risk of GDM and to improve pregnancy outcome. At present, metformin therapy in PCOS during pregnancy is considered experimental and metformin during pregnancy in PCOS is not yet generally recommended. A recent meta-analysis found that metformin improved live birth/ongoing pregnancy (RR, 1.28 (95\% CI, 1.01-1.63)) and clinical pregnancy rates (RR, 1.26 (95\% CI, 1.04-1.53)) when compared with placebo or no intervention (106), but the studies were of low quality and the effect of metformin was only modest. A randomized controlled trial in pregnant women with PCOS, comparing metformin to placebo, reported no significant difference in GDM prevalence $17.6 \%$ and $16.9 \%$, respectively (107); however, the study could have been underpowered to detect change in GDM prevalence. Recent studies reported that the use of metformin during pregnancy in PCOS was associated with higher head circumference in the offspring at birth (108) and higher BMI and increased prevalence of overweight/ obesity at 4 years of age (109).

At present, data are insufficient to decide if it is necessary to monitor glycemic status using OGTTs during metformin therapy in PCOS pregnancies, and it is too preliminary to apply the WHO2013 FPG threshold of $\geq 5.1 \mathrm{mmol} / \mathrm{L}$ (95) also in PCOS. Available data support that OGTT is probably not necessary in all pregnant women with PCOS whether untreated or on experimental metformin therapy.

\section{Conclusion against OGTT}

Glycemic status in PCOS may be evaluated by HbA1c, FPG or OGTT (71). BMI needs to be considered in PCOS as very few normal weight women are diagnosed with T2D. We need further data regarding prediabetes in PCOS and the impact of diagnosing IGT for future CVD, especially in young women with PCOS. At pre-pregnancy, glycemic 
status may be assessed by other methods than OGTT. During pregnancy, OGTT may not be indicated in lean women with PCOS without other risk factors.

In general, the indication for OGTT in PCOS resembles the indication in other populations at risk for T2D (71). In most instances, HbA1c or FPG may be applied instead of OGTT.

\section{Conclusion}

Data are quite convincing against recommending OGTT in normal-weight, non-pregnant women with PCOS, including during planning of pregnancy. This statement is in line with the rare use of OGTT for diagnosing diabetes or prediabetes in other populations at risk of T2D. In overweight women with PCOS, an OGTT may be the test of choice, especially if OGTT is readily available. However, it is necessary to take the low reproducibility of 2-h glucose measurements in OGTT into account and the risk of a false-positive diagnosis of IGT or T2D. In pregnancy, normal-weight women with PCOS do not seem to have increased risk of GDM. Prospective OGTTs, during follow-up in PCOS, including metformin and OCP therapy, is a matter of discussion. In our opinion, glycemic status may be evaluated by HbA1c in many cases.

\section{Declaration of interest}

The authors declare that there is no conflict of interest that could be perceived as prejudicing the impartiality of this debate.

\section{Funding}

This research did not receive any specific grant from any funding agency in the public, commercial or not-for-profit sector.

\section{References}

1 Conway G, Dewailly D, Diamanti-Kandarakis E, Escobar-Morreale HF, Franks S, Gambineri A, Kelestimur F, Macut D, Micic D, Pasquali R et al. The polycystic ovary syndrome: a position statement from the European Society of Endocrinology. European Journal of Endocrinology 2014171 1-29. (https://doi.org/10.1530/EJE-14-0253)

2 Glintborg D, Henriksen JE, Andersen M, Hagen C, Hangaard J, Rasmussen PE, Schousboe K \& Hermann AP. Prevalence of endocrine diseases and abnormal glucose tolerance tests in 340 Caucasian premenopausal women with hirsutism as the referral diagnosis. Fertility and Sterility 200482 1570-1579. (https://doi.org/10.1016/j. fertnstert.2004.06.040)

3 Rubin KH, Glintborg D, Nybo M, Abrahamsen B \& Andersen M. Development and risk factors of type 2 diabetes in a nationwide population of women with polycystic ovary syndrome. Journal of Clinical Endocrinology and Metabolism 2017102 3848-3857. (https:// doi.org/10.1210/jc.2017-01354)
4 Zhou Y, Wang X, Jiang Y, Ma H, Chen L, Lai C, Peng C, He C \& Sun C. Association between polycystic ovary syndrome and the risk of stroke and all-cause mortality: insights from a meta-analysis. Gynecological Endocrinology 201733 904-910. (https://doi.org/10.108 0/09513590.2017.1347779)

5 Anderson SA, Barry JA \& Hardiman PJ. Risk of coronary heart disease and risk of stroke in women with polycystic ovary syndrome: a systematic review and meta-analysis. International Journal of Cardiology 2014176 486-487. (https://doi.org/10.1016/j. ijcard.2014.06.079)

6 de Groot PC, Dekkers OM, Romijn JA, Dieben SW \& Helmerhorst FM. PCOS, coronary heart disease, stroke and the influence of obesity: a systematic review and meta-analysis. Human Reproduction Update 201117 495-500. (https://doi.org/10.1093/humupd/dmr001)

7 Zhao L, Zhu Z, Lou H, Zhu G, Huang W, Zhang S \& Liu F. Polycystic ovary syndrome (PCOS) and the risk of coronary heart disease (CHD): a meta-analysis. Oncotarget 20167 33715-33721. (https://doi. org/10.18632/oncotarget.13796)

8 Legro RS, Arslanian SA, Ehrmann DA, Hoeger KM, Murad MH, Pasquali R \& Welt CK. Diagnosis and treatment of polycystic ovary syndrome: an Endocrine Society clinical practice guideline. Journal of Clinical Endocrinology and Metabolism 201398 4565-4592. (https:// doi.org/10.1210/jc.2013-2350)

9 Rotterdam ESHRE/ASRM-Sponsored PCOS Consensus Workshop Group. Revised 2003 consensus on diagnostic criteria and long-term health risks related to polycystic ovary syndrome. Fertility and Sterility 200481 19-25.

10 Goodman NF, Cobin RH, Futterweit W, Glueck JS, Legro RS \& Carmina E. American Association of Clinical Endocrinologists, American College of Endocrinology, and Androgen Excess and PCOS Society Disease State Clinical Review: guide to the best practices in the evaluation and treatment of polycystic ovary syndrome. Endocrine Practices 201521 1415-1426. (https://doi.org/10.4158/ EP15748.DSCPT2)

11 Pelanis R, Mellembakken JR, Sundstrom-Poromaa I, Ravn P, MorinPapunen L, Tapanainen JS, Piltonen T, Puurunen J, Hirschberg AL, Fedorcsak P et al. The prevalence of Type 2 diabetes is not increased in normal-weight women with PCOS. Human Reproduction 201732 2279-2286. (https://doi.org/10.1093/humrep/dex294)

12 Roos N, Kieler H, Sahlin L, Ekman-Ordeberg G, Falconer H \& Stephansson $\mathrm{O}$. Risk of adverse pregnancy outcomes in women with polycystic ovary syndrome: population based cohort study. BMJ 2011 343 d6309. (https://doi.org/10.1136/bmj.d6309)

13 Pan ML, Chen LR, Tsao HM \& Chen KH. Relationship between polycystic ovarian syndrome and subsequent gestational diabetes mellitus: a nationwide population-based study. PLOS ONE 201510 e0140544. (https://doi.org/10.1371/journal.pone.0140544)

14 D McIntyre, DM Jensen, RC Jensen, HB Kyhl, TK Jensen, D Glintborg \& M Andersen. Gestational diabetes: does one size fit all? A challenge to uniform worldwide diagnostic thresholds. Diabetes Care 201841 1339-1342. (https://doi.org/10.2337/dc17-2393)

15 Palm CVB, Glintborg D, Kyhl HB, McIntyre HD, Jensen RC, Jensen TK, Jensen DM \& Andersen M. Polycystic ovary syndrome and hyperglycaemia in pregnancy. A narrative review and results from a prospective Danish cohort study. Diabetes Research and Clinical Practice 2018 Epub. (https://doi.org/10.1016/j.diabres.2018.04.030)

16 World Health Organisation. Definition, Diagnosis and Classification of Diabetes Mellitus and its Complications, 1999.

17 Sacks DB, Arnold M, Bakris GL, Bruns DE, Horvath AR, Kirkman MS, Lernmark A, Metzger BE \& Nathan DM. Executive summary: guidelines and recommendations for laboratory analysis in the diagnosis and management of diabetes mellitus. Clinical Chemistry 201157 793-798. (https://doi.org/10.1373/clinchem.2011.163634)

18 Legro RS, Kunselman AR, Dodson WC \& Dunaif A. Prevalence and predictors of risk for type 2 diabetes mellitus and impaired glucose 
tolerance in polycystic ovary syndrome: a prospective, controlled study in 254 affected women. Journal of Clinical Endocrinology and Metabolism 199984 165-169.

19 Hurd WW, Abdel-Rahman MY, Ismail SA, Abdellah MA, Schmotzer CL \& Sood A. Comparison of diabetes mellitus and insulin resistance screening methods for women with polycystic ovary syndrome. Fertility and Sterility 201196 1043-1047. (https:// doi.org/10.1016/j.fertnstert.2011.07.002)

20 American Diabetes Association. Diagnosis and classification of diabetes mellitus. Diabetes Care 201134 (Supplement 1) S62-S69.

21 Velling ML, Mumm H, Andersen M \& Glintborg D. Hemoglobin A1c as a tool for the diagnosis of type 2 diabetes in 208 premenopausal women with polycystic ovary syndrome. Fertility and Sterility 201196 1275-1280. (https://doi.org/10.1016/j.fertnstert.2011.08.035)

22 Peter A, Fritsche A, Stefan N, Heni M, Haring HU \& Schleicher E. Diagnostic value of hemoglobin A1c for type 2 diabetes mellitus in a population at risk. Experimental and Clinical Endocrinology and Diabetes 2011119 234-237. (https://doi. org/10.1055/s-0030-1270440)

23 Unwin N, Shaw J, Zimmet P \& Alberti KG. Impaired glucose tolerance and impaired fasting glycaemia: the current status on definition and intervention. Diabetic Medicine 200219 708-723. (https://doi.org/10.1046/j.1464-5491.2002.00835.x)

24 Cavagnolli G, Comerlato J, Comerlato C, Renz PB, Gross JL \& Camargo JL. HbA(1c) measurement for the diagnosis of diabetes: is it enough? Diabetic Medicine 201128 31-35. (https://doi.org/10.1111/ j.1464-5491.2010.03159.x)

25 Moran LJ, Misso ML, Wild RA \& Norman RJ. Impaired glucose tolerance, type 2 diabetes and metabolic syndrome in polycystic ovary syndrome: a systematic review and meta-analysis. Human Reproduction Update 201016 347-363. (https://doi.org/10.1093/ humupd/dmq001)

26 Tabak AG, Herder C, Rathmann W, Brunner EJ \& Kivimaki M. Prediabetes: a high-risk state for diabetes development. Lancet 2012 379 2279-2290. (https://doi.org/10.1016/S0140-6736(12)60283-9)

27 Barry E, Roberts S, Oke J, Vijayaraghavan S, Normansell R \& Greenhalgh T. Efficacy and effectiveness of screen and treat policies in prevention of type 2 diabetes: systematic review and meta-analysis of screening tests and interventions. BMJ 2017356 i6538. (https:// doi.org/10.1136/bmj.i6538)

28 Lim SS, Norman RJ, Davies MJ \& Moran LJ. The effect of obesity on polycystic ovary syndrome: a systematic review and meta-analysis. Obesity Reviews 201314 95-109. (https://doi.org/10.1111/j.1467789X.2012.01053.x)

29 Barber TM, Golding SJ, Alvey C, Wass JA, Karpe F, Franks S \& McCarthy MI. Global adiposity rather than abnormal regional fat distribution characterizes women with polycystic ovary syndrome. Journal of Clinical Endocrinology and Metabolism 200893 999-1004. (https://doi.org/10.1210/jc.2007-2117)

30 Clasey JL, Bouchard C, Teates CD, Riblett JE, Thorner MO, Hartman ML \& Weltman A. The use of anthropometric and dualenergy X-ray absorptiometry (DXA) measures to estimate total abdominal and abdominal visceral fat in men and women. Obesity Research 19997 256-264. (https://doi.org/10.1002/j.1550-8528.1999. tb00404.x)

31 Glintborg D. Endocrine and metabolic characteristics in polycystic ovary syndrome. Danish Medical Journal 201663 B5232.

32 Paradisi G, Smith L, Burtner C, Leaming R, Garvey WT, Hook G, Johnson A, Cronin J, Steinberg HO \& Baron AD. Dual energy $\mathrm{X}$-ray absorptiometry assessment of fat mass distribution and its association with the insulin resistance syndrome. Diabetes Care 1999 22 1310-1317. (https://doi.org/10.2337/diacare.22.8.1310)

33 Frederiksen L, Nielsen TL, Wraae K, Hagen C, Frystyk J, Flyvbjerg A, Brixen K \& Andersen M. Subcutaneous rather than visceral adipose tissue is associated with adiponectin levels and insulin resistance in young men. Journal of Clinical Endocrinology and Metabolism 200994 4010-4015. (https://doi.org/10.1210/jc.2009-0980)

34 Norman RJ, Masters L, Milner CR, Wang JX \& Davies MJ. Relative risk of conversion from normoglycaemia to impaired glucose tolerance or non-insulin dependent diabetes mellitus in polycystic ovarian syndrome. Human Reproduction 200116 1995-1998. (https://doi. org/10.1093/humrep/16.9.1995)

35 Glintborg D, Petersen MH, Ravn P, Hermann AP \& Andersen M. Comparison of regional fat mass measurement by whole body DXA scans and anthropometric measures to predict insulin resistance in women with polycystic ovary syndrome and controls. Acta Obstetricia et Gynecologica Scandinavica 201695 1235-1243. (https://doi. org/10.1111/aogs.12964)

36 Abdul-Ghani MA, Jenkinson CP, Richardson DK, Tripathy D \& Defronzo RA. Insulin secretion and action in subjects with impaired fasting glucose and impaired glucose tolerance: results from the Veterans Administration Genetic Epidemiology Study. Diabetes 2006 55 1430-1435. (https://doi.org/10.2337/db05-1200)

37 Ehrmann DA, Barnes RB, Rosenfield RL, Cavaghan MK \& Imperial J. Prevalence of impaired glucose tolerance and diabetes in women with polycystic ovary syndrome. Diabetes Care 199922 141-146. (https://doi.org/10.2337/diacare.22.1.141)

38 Legro RS, Gnatuk CL, Kunselman AR \& Dunaif A. Changes in glucose tolerance over time in women with polycystic ovary syndrome: a controlled study. Journal of Clinical Endocrinology and Metabolism 2005 90 3236-3242. (https://doi.org/10.1210/jc.2004-1843)

39 de Wilde MA, Goverde AJ, Veltman-Verhulst SM, Eijkemans MJ, Franx A, Fauser BC \& Koster MP. Insulin action in women with polycystic ovary syndrome and its relation to gestational diabetes. Human Reproduction 201530 1447-1453. (https://doi.org/10.1093/ humrep/dev072)

40 Lauenborg J, Hansen T, Jensen DM, Vestergaard H, MolstedPedersen L, Hornnes P, Locht H, Pedersen O \& Damm P. Increasing incidence of diabetes after gestational diabetes: a long-term follow-up in a Danish population. Diabetes Care 200427 1194-1199. (https:// doi.org/10.2337/diacare.27.5.1194)

41 Araujo JR, Keating E \& Martel F. Impact of gestational diabetes mellitus in the maternal-to-fetal transport of nutrients. Current Diabetes Reports 201515569.

42 Qin JZ, Pang LH, Li MJ, Fan XJ, Huang RD \& Chen HY. Obstetric complications in women with polycystic ovary syndrome: a systematic review and meta-analysis. Reproductive Biology and Endocrinology 201311 56. (https://doi.org/10.1186/1477-782711-56)

43 Finnbogadottir SK, Glintborg D, Jensen TK, Kyhl HB, Nohr EA \& Andersen M. Insulin resistance in pregnant women with and without polycystic ovary syndrome, and measures of body composition in offspring at birth and three years of age. Acta Obstetricia et Gynecologica Scandinavica 201796 1307-1314. (https://doi. org/10.1111/aogs.13200)

44 Wei D, Zhang B, Shi Y, Zhang L, Zhao S, Du Y, Xu L, Legro RS, Zhang $\mathrm{H}$ \& Chen ZJ. Effect of preconception impaired glucose tolerance on pregnancy outcomes in women with polycystic ovary syndrome. Journal of Clinical Endocrinology and Metabolism $2017 \mathbf{1 0 2}$ 3822-3829. (https://doi.org/10.1210/jc.2017-01294)

45 Orio F Jr, Palomba S, Spinelli L, Cascella T, Tauchmanova L, Zullo F, Lombardi G \& Colao A. The cardiovascular risk of young women with polycystic ovary syndrome: an observational, analytical, prospective case-control study. Journal of Clinical Endocrinology and Metabolism 200489 3696-3701. (https://doi.org/10.1210/jc.2003032049)

46 Glintborg D, Rubin KH, Nybo M, Abrahamsen B \& Andersen M. Cardiovascular disease in a nationwide population of Danish women with polycystic ovary syndrome. Cardiovascular Diabetology 201817 37. (https://doi.org/10.1186/s12933-018-0680-5) 
47 Glintborg D \& Andersen M. Management of endocrine disease: morbidity in polycystic ovary syndrome. European Journal of Endocrinology 2017176 R53-R65. (https://doi.org/10.1530/EJE-160373)

48 Rezaee M, Asadi N, Pouralborz Y, Ghodrat M \& Habibi S. A review on glycosylated hemoglobin in polycystic ovary syndrome. Journal of Pediatric and Adolescent Gynecology 201629 562-566. (https://doi. org/10.1016/j.jpag.2016.07.001)

49 Selvin E, Steffes MW, Zhu H, Matsushita K, Wagenknecht L, Pankow J, Coresh J \& Brancati FL. Glycated hemoglobin, diabetes, and cardiovascular risk in nondiabetic adults. New England Journal of Medicine 2010362 800-811. (https://doi.org/10.1056/ NEJMoa0908359)

50 Khaw KT, Wareham N, Bingham S, Luben R, Welch A \& Day N. Association of hemoglobin A1c with cardiovascular disease and mortality in adults: the European prospective investigation into cancer in Norfolk. Annals of Internal Medicine 2004141 413-420. (https://doi.org/10.7326/0003-4819-141-6-200409210-00006)

51 Levitan EB, Liu S, Stampfer MJ, Cook NR, Rexrode KM, Ridker PM, Buring JE \& Manson JE. HbA1c measured in stored erythrocytes and mortality rate among middle-aged and older women. Diabetologia 200851 267-275. (https://doi.org/10.1007/s00125-007-0882-y)

52 Sundstrom PI, Mellembakken JR, Papunen LM, Piltonen T, Puurunen J, Tapanainen JS, Stener-Victorin E, Hirschberg AL, Vanky E, Ravn P et al. Should we individualize lipid profiling in women with polycystic ovary syndrome? Human Reproduction 2016 31 2791-2795. (https://doi.org/10.1093/humrep/dew228)

53 Mani H, Levy MJ, Davies MJ, Morris DH, Gray LJ, Bankart J, Blackledge H, Khunti K \& Howlett TA. Diabetes and cardiovascular events in women with polycystic ovary syndrome: a 20-year retrospective cohort study. Clinical Endocrinology $2013 \mathbf{7 8} 926-934$ (https://doi.org/10.1111/cen.12068)

54 Glintborg D, Mumm H, Ravn P \& Andersen M. Age associated differences in prevalence of individual Rotterdam criteria and metabolic risk factors during reproductive age in 446 Caucasian women with polycystic ovary syndrome. Hormone and Metabolic Research 201244 694-698. (https://doi.org/10.1055/s-0032-1304608

55 Moretti C, Lanzolla G, Moretti M, Gnessi L \& Carmina E. Androgens and hypertension in men and women: a unifying view. Current Hypertension Reports 201719 44. (https://doi.org/10.1007/s11906017-0740-3)

56 Valkenburg O, Steegers-Theunissen RP, Smedts HP, Dallinga-Thie GM, Fauser BC, Westerveld EH \& Laven JS. A more atherogenic serum lipoprotein profile is present in women with polycystic ovary syndrome: a case-control study. Journal of Clinical Endocrinology and Metabolism 200893 470-476. (https://doi.org/10.1210/jc.2007-1756)

57 Wiltgen D \& Spritzer PM. Variation in metabolic and cardiovascular risk in women with different polycystic ovary syndrome phenotypes Fertility and Sterility 201094 2493-2496. (https://doi.org/10.1016/j. fertnstert.2010.02.015)

58 Gunning MN \& Fauser BCJM. Are women with polycystic ovary syndrome at increased cardiovascular disease risk later in life? Climacteric 201720 222-227. (https://doi.org/10.1080/13697137.201 7.1316256)

59 Meun C, Franco OH, Dhana K, Jaspers L, Muka T, Louwers Y, Ikram MA, Fauser BCJM, Kavousi M \& Laven JSE. High androgens in postmenopausal women and the risk for atherosclerosis and cardiovascular disease: the Rotterdam Study. Journal of Clinical Endocrinology and Metabolism 2018103 1622-1630. (https://doi. org/10.1210/jc.2017-02421)

60 Mallett S, Halligan S, Thompson M, Collins GS \& Altman DG. Interpreting diagnostic accuracy studies for patient care. BMJ 2012 345 e3999. (https://doi.org/10.1136/bmj.e3999)

61 Ollila ME, West S, Keinanen-Kiukaanniemi S, Jokelainen J, Auvinen J, Puukka K, Ruokonen A, Jarvelin MR, Tapanainen JS, Franks S et al. Overweight and obese but not normal weight women with PCOS are at increased risk of Type 2 diabetes mellitus-a prospective, population-based cohort study. Human Reproduction 201732 423-431. (https://doi.org/10.1093/humrep/dew329)

62 Lerchbaum E, Schwetz V, Giuliani A \& Obermayer-Pietsch B. Assessment of glucose metabolism in polycystic ovary syndrome: $\mathrm{HbA1c}$ or fasting glucose compared with the oral glucose tolerance test as a screening method. Human Reproduction 201328 2537-2544. (https://doi.org/10.1093/humrep/det255)

63 Vrbikova J, Fanta M, Cibula D, Vondra K \& Bendlova B. Impaired glucose metabolism in women with polycystic ovary syndrome. Gynecologic and Obstetric Investigation 200968 186-190. (https://doi. org/10.1159/000232574)

64 Celik C, Tasdemir N, Abali R, Bastu E \& Yilmaz M. Progression to impaired glucose tolerance or type 2 diabetes mellitus in polycystic ovary syndrome: a controlled follow-up study. Fertility and Sterility 2014101 1123-1128. (https://doi.org/10.1016/j. fertnstert.2013.12.050)

65 Boudreaux MY, Talbott EO, Kip KE, Brooks MM \& Witchel SF. Risk of T2DM and impaired fasting glucose among PCOS subjects: results of an 8-year follow-up. Current Diabetes Reports 20066 77-83. (https:// doi.org/10.1007/s11892-006-0056-1)

$66 \mathrm{Li} \mathrm{W} \& \mathrm{Li}$ Q. Dysregulation of glucose metabolism even in Chinese PCOS women with normal glucose tolerance. Endocrine Journal 2012 59 765-770. (https://doi.org/10.1507/endocrj.EJ12-0049)

$67 \mathrm{Li} \mathrm{W}, \mathrm{Ma} \mathrm{L} \& \mathrm{Li} \mathrm{Q}$. Insulin resistance but not impaired beta-cell function: a key feature in Chinese normal-weight PCOS women with normal glucose regulation. Gynecological Endocrinology 201228 598-601. (https://doi.org/10.3109/09513590.2011.650757)

68 Moran LJ, Norman RJ \& Teede HJ. Metabolic risk in PCOS: phenotype and adiposity impact. Trends in Endocrinology and Metabolism 201526 136-143. (https://doi.org/10.1016/j.tem.2014.12.003)

69 Corbould A. Effects of androgens on insulin action in women: is androgen excess a component of female metabolic syndrome? Diabetes/Metabolism Research and Reviews 200824 520-532. (https:// doi.org/10.1002/dmrr.872)

70 Li H, Li L, Gu J, Li Y, Chen X \& Yang D. Should all women with polycystic ovary syndrome be screened for metabolic parameters? A hospital-based observational study. PLOS ONE 201611 e0167036. (https://doi.org/10.1371/journal.pone.0167036)

71 American Diabetes Association. Classification and diagnosis of diabetes. Diabetes Care 201740 S11-S24.

72 Schousboe K, Henriksen JE, Kyvik KO, Sorensen TI \& Hyltoft PP. Reproducibility of S-insulin and B-glucose responses in two identical oral glucose tolerance tests. Scandinavian Journal of Clinical and Laboratory Investigation 200262 623-630. (https://doi. org/10.1080/003655102764654358)

73 Olabi B \& Bhopal R. Diagnosis of diabetes using the oral glucose tolerance test. BMJ 2009339 b4354. (https://doi.org/10.1136/bmj. b4354)

74 Sicree RA, Zimmet PZ, Dunstan DW, Cameron AJ, Welborn TA \& Shaw JE. Differences in height explain gender differences in the response to the oral glucose tolerance test - the AusDiab study. Diabetic Medicine 200825 296-302. (https://doi.org/10.1111/j.14645491.2007.02362.x)

75 International Expert Committee. International Expert Committee report on the role of the $\mathrm{A} 1 \mathrm{C}$ assay in the diagnosis of diabetes. Diabetes Care 200932 1327-1334.

76 Jorgensen LG, Brandslund I \& Hyltoft PP. Should we maintain the 95 percent reference intervals in the era of wellness testing? A concept paper. Clinical Chemistry and Laboratory Medicine 200442 747-751.

77 Cinar N, Kizilarslanoglu MC, Harmanci A, Aksoy DY, Bozdag G, Demir B \& Yildiz BO. Depression, anxiety and cardiometabolic risk in polycystic ovary syndrome. Human Reproduction 201126 3339-3345. (https://doi.org/10.1093/humrep/der338)

78 Altinok ML, Glintborg D, Depont CR, Hallas J \& Andersen M. Prescription of antidepressants is increased in Danish patients with 
polycystic ovary syndrome and is associated with hyperandrogenism. A population-based cohort study. Clinical Endocrinology $2013 \mathbf{8 0}$ 884-889. (https://doi.org/10.1111/cen.12365)

79 Libby P, Ridker PM \& Maseri A. Inflammation and atherosclerosis. Circulation 2002105 1135-1143. (https://doi.org/10.1161/ hc0902.104353)

80 Eckel RH, Alberti KG, Grundy SM \& Zimmet PZ. The metabolic syndrome. Lancet 2010375 181-183. (https://doi.org/10.1016/ S0140-6736(09)61794-3)

81 Febbraio M, Hajjar DP \& Silverstein RL. CD36: a class B scavenger receptor involved in angiogenesis, atherosclerosis, inflammation, and lipid metabolism. Journal of Clinical Investigation 2001108 785-791. (https://doi.org/10.1172/JCI14006)

82 Glintborg D, Hojlund K, Andersen M, Henriksen JE, Beck-Nielsen H \& Handberg A. Soluble CD36 and risk markers of insulin resistance and atherosclerosis are elevated in polycystic ovary syndrome and significantly reduced during pioglitazone treatment. Diabetes Care 200831 328-334. (https://doi.org/10.2337/dc07-1424)

83 Toulis KA, Goulis DG, Mintziori G, Kintiraki E, Eukarpidis E, Mouratoglou SA, Pavlaki A, Stergianos S, Poulasouchidou M, Tzellos TG et al. Meta-analysis of cardiovascular disease risk markers in women with polycystic ovary syndrome. Human Reproduction Update 201117 741-760. (https://doi.org/10.1093/humupd/dmr025)

84 Kivimaki M \& Tabak AG. Does addressing prediabetes help to improve population health? Lancet Diabetes and Endocrinology 20186 354-356. (https://doi.org/10.1016/S2213-8587(18)30030-5).

85 Vistisen D, Witte DR, Brunner EJ, Kivimaki M, Tabak A, Jorgensen ME $\&$ Faerch K. Risk of cardiovascular disease and death in individuals with prediabetes defined by different criteria: The Whitehall II Study. Diabetes Care 201841 899-906. (https://doi.org/10.2337/dc17-2530)

86 Moran LJ, Pasquali R, Teede HJ, Hoeger KM \& Norman RJ. Treatment of obesity in polycystic ovary syndrome: a position statement of the Androgen Excess and Polycystic Ovary Syndrome Society. Fertility and Sterility 200992 1966-1982. (https://doi.org/10.1016/j. fertnstert.2008.09.018

87 Costello M, Shrestha B, Eden J, Sjoblom P \& Johnson N. Insulinsensitising drugs versus the combined oral contraceptive pill for hirsutism, acne and risk of diabetes, cardiovascular disease, and endometrial cancer in polycystic ovary syndrome. Cochrane Database of Systematic Reviews 2007 CD005552.

88 Glintborg D, Altinok ML, Mumm H, Hermann AP, Ravn P \& Andersen M. Body composition is improved during 12 months' treatment with metformin alone or combined with oral contraceptives compared with treatment with oral contraceptives in polycystic ovary syndrome. Journal of Clinical Endocrinology and Metabolism 201499 2584-2591. (https://doi.org/10.1210/jc.20141135)

89 Glintborg D, Mumm H, Altinok ML, Richelsen B, Bruun JM \& Andersen M. Adiponectin, interleukin-6, monocyte chemoattractant protein-1, and regional fat mass during 12-month randomized treatment with metformin and/or oral contraceptives in polycystic ovary syndrome. Journal of Endocrinological Investigation 201437 757-764. (https://doi.org/10.1007/s40618-014-0103-8)

90 Glintborg D, Mumm H, Holst JJ \& Andersen M. Effect of oral contraceptives and/or metformin on GLP-1 secretion and reactive hypoglycaemia in polycystic ovary syndrome. Endocrine Connections 20176 267-277. (https://doi.org/10.1530/EC-17-0034)

91 Tomlinson J, Millward A, Stenhouse E \& Pinkney J. Type 2 diabetes and cardiovascular disease in polycystic ovary syndrome: what are the risks and can they be reduced? Diabetic Medicine 201027 498-515. (https://doi.org/10.1111/j.1464-5491.2010.02994.x)

92 Sharma ST, Wickham EP III \& Nestler JE. Changes in glucose tolerance with metformin treatment in polycystic ovary syndrome: a retrospective analysis. Endocrine Practices 200713 373-379. (https:// doi.org/10.4158/EP.13.4.373)
93 Sahin Y, Unluhizarci K, Yilmazsoy A, Yikilmaz A, Aygen E $\&$ Kelestimur F. The effects of metformin on metabolic and cardiovascular risk factors in nonobese women with polycystic ovary syndrome. Clinical Endocrinology 200767 904-908. (https://doi. org/10.1111/j.1365-2265.2007.02985.x)

94 Halperin IJ, Kumar SS, Stroup DF \& Laredo SE. The association between the combined oral contraceptive pill and insulin resistance, dysglycemia and dyslipidemia in women with polycystic ovary syndrome: a systematic review and meta-analysis of observational studies. Human Reproduction 201126 191-201. (https://doi. org/10.1093/humrep/deq301)

95 Diagnostic criteria and classification of hyperglycaemia first detected in pregnancy: a World Health Organization Guideline. Diabetes Research and Clinical Practice 2014103 341-363.

96 Benhalima K, Mathieu C, Van AA, Damm P, Devlieger R, Mahmood T $\&$ Dunne F. Survey by the European Board and College of Obstetrics and Gynaecology on screening for gestational diabetes in Europe. European Journal of Obstetrics and Gynecology and Reproductive Biology 2016201 197-202. (https://doi.org/10.1016/j.ejogrb.2016.04.003)

97 Jensen DM, Molsted-Pedersen L, Beck-Nielsen H, Westergaard JG, Ovesen P \& Damm P. Screening for gestational diabetes mellitus by a model based on risk indicators: a prospective study. American Journal of Obstetrics and Gynecology 2003189 1383-1388. (https://doi. org/10.1067/S0002-9378(03)00601-X)

98 Kyhl HB, Jensen TK, Barington T, Buhl S, Norberg LA, Jorgensen JS, Jensen DF, Christesen HT, Lamont RF \& Husby S. The Odense Child Cohort: aims, design, and cohort profile. Paediatric and Perinatal Epidemiology 201529 250-258. (https://doi.org/10.1111/ppe.12183)

99 Lo JC, Yang J, Gunderson EP, Hararah MK, Gonzalez JR \& Ferrara A. Risk of type 2 diabetes mellitus following gestational diabetes pregnancy in women with polycystic ovary syndrome. Journal of Diabetes Research 20172017 5250162. (https://doi. org/10.1155/2017/5250162)

100 Escobar-Morreale HF, Santacruz E, Luque-Ramirez M \& Botella Carretero JI. Prevalence of 'obesity-associated gonadal dysfunction' in severely obese men and women and its resolution after bariatric surgery: a systematic review and meta-analysis. Human Reproduction Update 201723 390-408. (https://doi.org/10.1093/humupd/dmx012)

101 Skubleny D, Switzer NJ, Gill RS, Dykstra M, Shi X, Sagle MA, de GC, Birch DW \& Karmali S. The impact of bariatric surgery on polycystic ovary syndrome: a systematic review and meta-analysis. Obesity Surgery 201626 169-176. (https://doi.org/10.1007/s11695015-1902-5)

102 Kjaer MM, Madsbad S, Hougaard DM, Cohen AS \& Nilas L. The impact of gastric bypass surgery on sex hormones and menstrual cycles in premenopausal women. Gynecological Endocrinology 201733 160-163. (https://doi.org/10.1080/09513590.2016.1236243)

103 Gonzalez I, Lecube A, Rubio MA \& Garcia-Luna PP. Pregnancy after bariatric surgery: improving outcomes for mother and child. International Journal of Women's Health 20168 721-729. (https://doi. org/10.2147/IJWH.S99970)

104 Adam S, Ammori B, Soran H \& Syed AA. Pregnancy after bariatric surgery: screening for gestational diabetes. BMJ $2017 \mathbf{3 5 6}$ j533. (https://doi.org/10.1136/bmj.j533)

105 Feichtinger M, Stopp T, Hofmann S, Springer S, Pils S, KautzkyWiller A, Kiss H, Eppel W, Tura A, Bozkurt L \& Gobl CS. Altered glucose profiles and risk for hypoglycaemia during oral glucose tolerance testing in pregnancies after gastric bypass surgery. Diabetologia 201760 153-157. (https://doi.org/10.1007/s00125-0164128-8)

106 Kollmann M, Martins WP, Lima ML, Craciunas L, Nastri CO, Richardson A \& Raine-Fenning N. Strategies for improving outcome of assisted reproduction in women with polycystic ovary syndrome: systematic review and meta-analysis. Ultrasound in Obstetrics and Gynecology 201648 709-718. (https://doi.org/10.1002/uog.15898) 
107 Vanky E, Stridsklev S, Heimstad R, Romundstad P, Skogoy K, Kleggetveit O, Hjelle S, von BP, Eikeland T, Flo K, Berg KF et al. Metformin versus placebo from first trimester to delivery in polycystic ovary syndrome: a randomized, controlled multicenter study. Journal of Clinical Endocrinology and Metabolism 201095 E448-E455. (https://doi.org/10.1210/jc.2010-0853)

108 Hjorth-Hansen A, Salvesen O, Engen Hanem LG, Eggebo T, Salvesen KA, Vanky E \& Odegard R. Fetal growth and birth anthropometrics in metformin-exposed offspring born to mothers with PCOS. Journal of Clinical Endocrinology and Metabolism 2018103 740-747. (https://doi.org/10.1210/jc.2017-01191)

109 Engen Hanem LG, Stridsklev S, Juliusson PB, Salvesen O, Roelants M, Carlsen SM, Odegard R \& Vanky E. Metformin use in PCOS

pregnancies increases the risk of offspring overweight at 4 years of age; follow-up of two RCTs. Journal of Clinical Endocrinology and Metabolism 2018103 1612-1621. (https://doi.org/10.1210/jc.2017-02419)

Received 20 March 2018

Revised version received 10 June 2018

Accepted 18 June 2018 